\title{
Marine Os isotope record during the Eocene hyperthermals in the Indian Ocean: Implication for continental silicate weathering feedback
}

ERIKA TANAKA ${ }^{1}$, KAZUTAKA YASUKAWA ${ }^{1,2}$, JUNICHIRO OHTA $^{1,2}$, KENTARO NAKAMURA $^{1}$, GREGORY RAVIZZA ${ }^{3}$ AND YASUHIRO KATO ${ }^{1,2 *}$

${ }^{1}$ School of Engineering, The University of Tokyo, Japan ${ }^{2}$ Ocean Resources Research Center for Next Generation, Chiba Institute of Technology, Japan

${ }^{3}$ University of Hawai' $i$ at Mānoa, USA

(*ykato@sys.t.u-tokyo.ac.jp)

Multiple global warminig events occurred during the early Paleogene, which are called "hyperthermals". They are characterized by negative carbon isotope excursions (CIEs) and short-term durations $\left(<10^{5}\right.$ years) [1]. In general, during a global warming, excess atmospheric $\mathrm{CO}_{2}$ is sequestered by Earth system's negative feedback such as increasing (1) marine productivity and (2) chemical weathering of continental silicates. A previous study reported the increases of marine productivity effectively worked for the multiple hyperthermal events during the early Eocene [2]. However, evidence for intensification of the silicate weathering has been reported only for the Paleocene-Eocene Thermal Maximum (PETM) [3] and the Eocene Thermal Maximum 2 (ETM2) [4].

We will report marine Os isotope records of ODP Site 752 in the Indian Ocean during the early Eocene including the ETM2, I1 event and ETM3. Os isotopic ratio of seawater has been used as an indicator of the intensity of continental silicate weathering [3, 4]. In the presentation, we will discuss whether the silicate weathering feedback functioned during relatively smaller warming events than PETM and ETM2.

[1] Cramer et al. (2003) Paleoceanography, 18(4), 1097.

[2] Yasukawa et al. (2017) Scientific Reports, 7, 11304.

[3] Ravizza et al. (2001) Paleoceanography, 16(2), 155-163.

[4] Peucker-Ehrenbrink and Ravizza (2012) In Geologic Time Scale 2012. 